\title{
Augmented Reality Experience for Inaccessible Areas in Museums
}

\author{
Claudio Germak \\ Politecnico di Torino \\ Italy \\ claudio.germak@polito.it
}

\author{
Andrea Di Salvo \\ Politecnico di Torino \\ Italy \\ andrea.disalvo@polito.it
}

\author{
Lorenza Abbate \\ Politecnico di Torino \\ Italy \\ lorenza.abbate@polito.it
}

\begin{abstract}
In recent years, new innovations have been introduced into the cultural heritage sector, aimed at offering more engaging and accessible tours to the public. The article discusses the development process of the VirgilTell project, for the visit of inaccessible places in the Racconigi Castle, one of the Savoy residences in Piedmont (Italy), by the UXD Team of Politecnico di Torino. The places assigned to the project are being restored and therefore excluded from the tour. The VirgilTell experience aims to include and make them accessible to visitors, through a virtual tour including multimedia content for the entertainment and involvement of the users. The visit has been realised through mixed techniques between VR and AR for the narration of the spaces in which the user takes part in a journey made of narratives by characters from the past and objects that no longer exist. The VirgilTell visit was also created with the aim of anticipating, in promotional terms, the physical visit to the museum spaces undergoing restoration, so as to attract visitors back inside once the work is finished.
\end{abstract}

Design for heritage. Augmented reality. Human centered design. User experience design. Digital storytelling.

\section{INTRODUCTION}

The introduction of digital technologies into cultural heritage is witnessing a significant paradigm shift in museology: from a model with conservation purposes, where works were simply physically displayed, to one that allows for a mixed-use offer, both in presence and at a remote location (Kargas, Karitsioti \& Loumos 2020). Museum institutions are investing in cultural heritage mediated by digital technologies to establish a new dialogue between visitors, with evolving needs, and the spaces they visit. The aim is to create storytelling experiences that make spaces engaging, immersive and interactive.

The technologies allow different levels of immersion in the new realities, digitally mediated and replicated, depending on the perceptual involvement that is intended to be achieved by the users, the characteristics of the activity to be included in the context and consequently the device to be adopted (Koslow 2019).

In this evolving scenario, it is crucial to ensure that accessibility to cultural heritage, both tangible and intangible, can be provided to all visitors, regardless of their physical/cognitive abilities. The concept of accessibility is a key element to take into account when approaching the design of activities aimed at the use of museum spaces; in fact, institutions and research are moving in this direction, trying to respond to the different needs of users through a design-for-all approach.

Therefore, factors that may affect accessibility in museums should be considered, so that they can be overcome through the use of digital technology. Among these factors we find non-compliance with the regulations of the places, architectural barriers, restoration works, the existence of collections of goods not yet ready for display, cognitive and cultural barriers. In this sense, digital technologies can be a key tool in promoting standards of inclusion, if contextualised in a conscious way, for the enjoyment of cultural heritage (Chung et al. 2017). Through the combination of innovative forms of edutainment and experiential learning, we arrive at the creation of experiences for visitors, which allow for a fruition of content, even of a technical nature, in a simplified and informative mode with new forms of "reality" (Tscheu \& Buhalis 2016).

Among the growing technologies applied to the museum sector are Virtual Reality and Augmented Reality, whose features allow total visitor immersion and provide entertainment experiences, which facilitate a new museology based on personalisation and customised experience (Southall, Marmion \& Davies 2019). VR and AR 
aim to support the acquisition of knowledge through concrete experimentation, reflection and abstraction, which are generally difficult to acquire when viewing environments and artefacts from the past (Bekele et al. 2018). Visitors have the opportunity to get in touch with the past, with all their senses, experiencing places and objects through their own gestures. By exploiting the potential offered by these technologies it is possible to implement and improve the communication of cultural heritage by making the offer more attractive and accessible to different groups of users.

The VirgilTell project was born with the aim of allowing the public to enjoy temporarily inaccessible museum spaces, in order to create a visit model scalable in other similar contexts, considering that the topic is substantial enough on the Italian scene. In fact, in terms of accessibility, the Italian museum heritage still presents physical and sensory barriers that prevent people with disabilities from fully accessing the available cultural resources. Only half of the Italian museums $(53 \%)$ are equipped to guarantee the accessibility of the spaces and the usability of the collections to users with disabilities (Istat 2019).

\section{RELATED WORK}

Since the early 2000s, immersive augmented, virtual and mixed reality technologies have become part of the museum offer, providing a sensory experience to visitors through combinations of real and digital content. Users have the possibility to experience cultural artefacts in a completely new way.

The contamination of technologies within the museum context led the user to get involve in different levels of experience, combining the dimension of traditional cultural models with that of unusual and evolving experiences (Pine \& Gilmour, 1998). The disruptive power of new technologies redesigned the museum offer and its services, enhancing the figure of the visitor who becomes the protagonist and proactive explorer of his/her visit. Access to heritage, preservation and enhancement through technological advances are topics in continuous evolution and experimentation that are beginning to open up in collaborations between different disciplines. Even in Italy, the scenarios of the application of these immersive technologies are starting to open up more and more, especially in an area where heritage museums contribute to the education and cultural, ethical and civil formation of individuals and society as a whole (Sacco et al., 2013).

Through experimentation with VR and $A R$, museum visitors are introduced to exciting immersive and interactive experiences. These experiences transport audiences into a world where they are able to become part of the environment and access simplified content, even for the non-expert audience. Museum organisations are investing in the development of VR and AR experiences to be included in their offer, trying to overcome environmental limitations and provide new opportunities for virtualisation, also thanks to the simplicity and flexibility of updating these tools (Schaper et al. 2018). In fact, these new realities allow, in addition to the documentation and cataloguing of assets, different forms of exploration in knowledge enrichment: reconstruction and narration of places, architectures and objects that are no longer there or have never existed, but also, it may seem a paradox, access to places that exist but are inaccessible.

Inaccessibility therefore becomes an opportunity to experiment with new forms of communication, from storytelling to gaming, through the use of VR and $A R$, optimised in relation to the characteristics of the user groups. These aspects emerge from the different experiences that have been created in the different museums. Among the VR experiences is one presented at the British Museum in 2015 that was created around exploring and describing the Bronze Age to visitors (Rae \& Edwards 2016). The virtual reality environment aimed to increase public interest and excitement in the Bronze Age objects being shown and experienced. The creation of a Bronze Age environment allowed the value of VR to be tested to enhance visitors' understanding of a historical collection, where much of the evidence is archaeological. So, the choice of a VR experience was to add value to building knowledge of this period, especially to specific audiences such as schools and families.

The Ara Pacis Museum in Rome introduced new practices of cultural heritage display based on the use of tools including $A R$ and VR, designing the experience "The Ara As It Was". The experience was installed on the monument 'Ara' and was developed in collaboration with an international digital and creative company. The project aimed to create a learning experience for visitors to the museum, bringing the reliefs of the Ara to life, making them regain their original splendour and colours. A project that sought to bring to light the old splendour of monuments worn out by the passage of time and bring them back to life in the present.

ArkaeVision Archeo is a VR experience designed to engage users in a circular and interactive way, where it is possible to virtually visit the temple dedicated to Hera II in Paestum, in the first half of the 5th century BC (Bozzelli et. al 2019). Users are taken on a journey that will lead them on a virtual tour where the beliefs, values and ancient population of the city of Magna Graecia are presented. There 
are mainly two modes of exploration: a semi-guided visit by the digital actor, with the possibility to explore; and a free and more didactic one, where events and facts evolve in the plot, capturing their attention and pushing them to follow the path.

\section{VIRGILTELL: AR AND VR EXPERIENCE}

VirgilTell is a mixed experience, between VR and $A R$, born within the project Les Ducs des Alpes / I Duchi delle Alpi, financed in the framework of the cross-border cooperation programme between France and Italy ALCOTRA, to increase the tourist attraction of visiting the territories between Piedmont and France, building an itinerary around the historical places of the House of Savoy.

The VirgilTell project was born with the purpose of tackling the issue of accessibility of the temporary closed areas of Racconigi Castle in Piedmont, which cannot be visited by the public, and the subsequent scalability of the experience in the other Savoy residences in order to create a network among them.

VirgilTell comes as a follow-up to the Virgil project (Lupetti, Germak \& Giuliano, 2015), a telepresence robot designed for the exploration of inaccessible areas, also inside Racconigi Castle, led by the UXD Polito research team. The robot was designed for some rooms of the castle that are excluded from visits mainly because of their state of preservation, fragility and logistical management. Virgil, driven by a Museum Guide, conducted a tour inside the spaces, sending live images mixed with multimedia compendium on screen to the visitors. In this case the experience is lived by the end users with the contribution of specialised operators. The activity has therefore become more complex both on an experimental level, bringing to light various technological limits, and on an economic and service management level. Other limitations of the telepresence robot within the environments included: the instability of the connection for piloting the robot, particularly in environments bordered by thick walls, the instability of on-board camera, the need for specialised technical assistance to solve accidental problems with the robot, and the level of interaction of the visitor with the robot, assessed through ethnographic tests as "low".

These considerations were instrumental in the development of the VirgilTell experience, focusing on the exploration of other inaccessible places in the Castle through VR and AR. This has made it possible to make accessible places excluded from visits because they have been restored and to give them a new life.

The condition of conservative restoration is common to many museums, which had to close parts of the tours because they were not safe for users. The VirgilTell experience intends to replace only temporarily those areas that cannot be visited by users, providing a different, augmented and interactive experience.

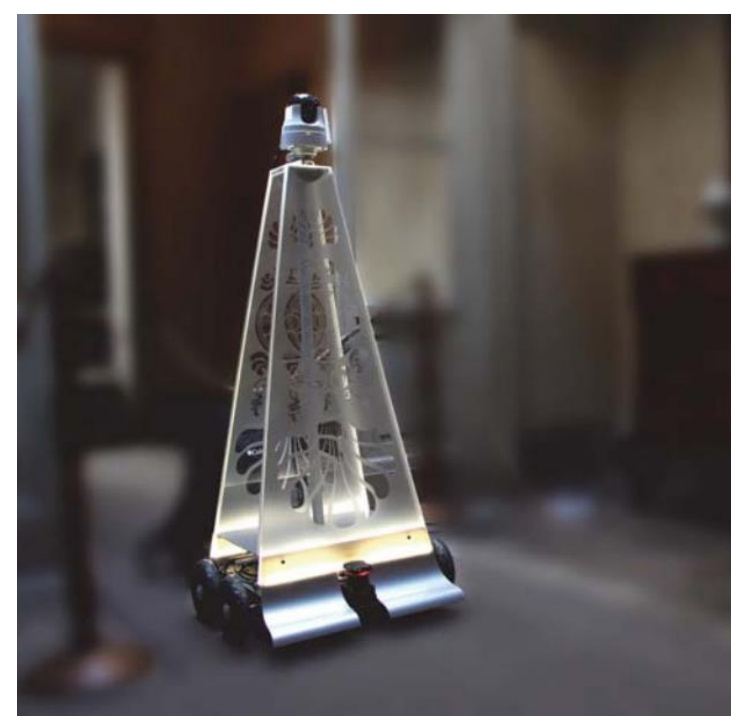

Figure 1: Virgil Robot

Unlike robotics, the new solution aims at the ease of scaling up and replicating the experience in a simple and fast way, adapting the contents to other places, without the need to employ significant amounts of resources in terms of money and time. The research team, made up of designers, was supported from the earliest stages of the project by various disciplines including architecture and art history, with the aim of arriving at a product shared and accepted by the users and stakeholders of the system. This strategy was also conceived with a view to showing the rooms before restoration, and then attracting visitors again once the worksite has been completed.

\subsection{The Historical Background}

Racconigi Castle, located in Piedmont, was built in the 11th century and was one of the residences of the Royal Savoy family. In the 19th century King Carlo Alberto of Savoia-Carignano made substantial changes to the structure that made it a "Royal Holiday Home" (Roggero \& Vanelli, 2009). For this occasion, Carlo Alberto called the architect and decorator Pelagio Palagi to the court for the work, in order to assign him the design of the interior furnishings and ornaments in neoclassical style, first only for the areas of the expanding castle, then for all the Savoy residences. The architect Pelagio Palagi was responsible for the design of several rooms, including King Carlo Alberto's thermal baths, a particularly prestigious environment inspired by the Roman thermal baths, where he designed both the frescoes on the walls of the rooms inside, representing classical 
mythological scenes, and all the furnishings that had been lost over the years. The thermal baths were later implemented and improved by King Vittorio Emanuele III, who in the early 1900s brought them to new splendour by introducing technological innovations of the time. From that time on, the baths did not undergo any more transformations and restorations and were abandoned for a long time, suffering significant damage caused by the dampness of the rooms.

In 2020, work started on the conservative restoration of the thermal baths of Carlo Alberto, which led to the creation of the VirgilTell project for a virtual visit to the places being restored. This strategy was also conceived with a view to show the rooms before restoration, and then attracting visitors again once the worksite has been completed.

\section{VIRGILTELL DEVELOPMENT}

The development of VirgilTell's platform for remote access to inaccessible areas involved an initial stage of scenario analysis with the introduction of case studies on Augmented Reality and Virtual Reality applied to cultural heritage.

From the scenario analysis emerged the requirements that guided the development of the project, which has seen the application of a human centered approach, for the understanding of the needs of users and stakeholders involved in the activity, not yet widespread enough in these experiences, which are linked to a technocentric vision (Barbieri, Bruno \& Muzzupappa, 2017).

The VirgilTell project had the following objectives: offer the opportunity to visit temporarily inaccessible places, create a scalable model and adopt a digital medium contextual to the message to be transmitted. The experience involved the use of Oculus Quest visors, tools for the reproduction of virtual reality, capable of introducing suggestions that would otherwise be impossible, attracting visitors of all ages and levels of knowledge (technological and historical) and making them experience the atmosphere of the castle. The historical framework of the places to be rendered within the experience was fundamental in the early stages of the project, through textual and iconographic studies of the architecture and customs of the period. To do this, the team used the support of historians, who were able to provide and verify the truthfulness of the information to be included. Once the framework of information was systematised, the contents useful for the narration of the visit experience were selected.

The mixed technique between $V R$ and $A R$ appeared to be the most suitable for the narration of spaces, existing from the architectural point of view, but now devoid of furniture and furnishings. The scenography of the experience is in fact constituted by the images of the rooms in their pre-restoration state, augmented by the introduction of characters, moving machines and objects from the past.

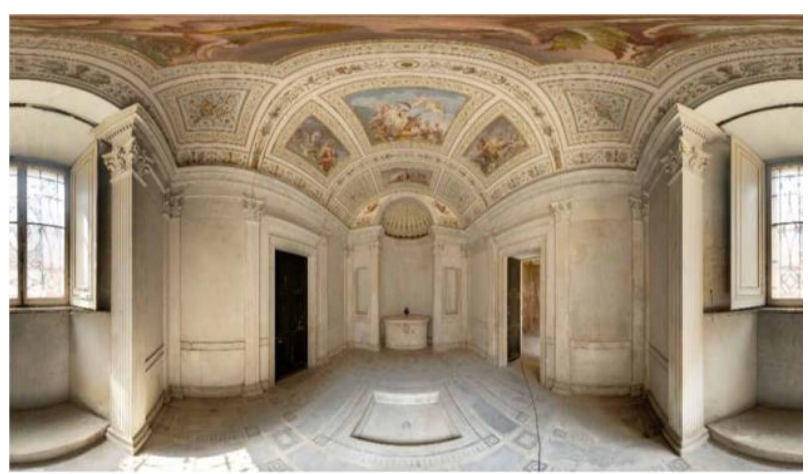

Figure 2: King Carlo Alberto's thermal baths in prerestoration phase

The different steps of the project included a photogrammetric reconstruction of the environments, cleaned of transfigurative and obscuring elements, through $360^{\circ}$ images. In the 3D rebuilding operation, the images were superimposed on the meshes of the simplified volumes of the thermal baths of Carlo Alberto. The environments were reconstructed in $3 \mathrm{D}$ on the modelling program Blender, and the result obtained was integrated with the elements useful for the scenography: from the lighting, which gives a dark and mysterious photography, to the furniture and objects of the scene. The project attempted to digitally reconstruct the furnishings that were present at the time in those places, now destroyed, through the drawings and inventories of the architect Pelagio Palagi.

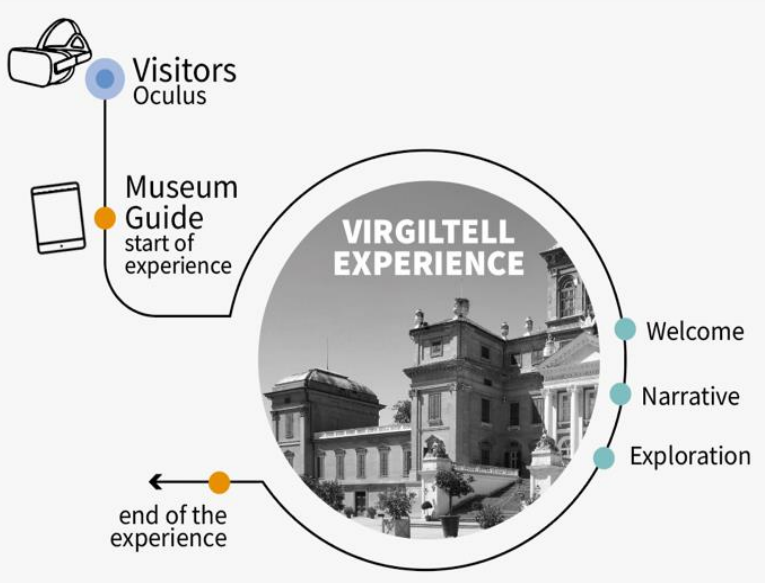

Figure 3: General schema of VirgilTell experience

The visiting experience in the virtual space is accompanied by various "ghost" style characters, who stop off in the rooms by appearing from a cloud. The characters appearing in the plot are the ghosts of King Carlo Alberto and King Vittorio Emanuele II, who are among the royal personalities who contributed most to the construction of the thermal flats. They are joined by an entirely imaginary figure, the maid Benedetta, who has 
contributed to the informative-didactic and narrative enrichment of the virtual experience, lightening the stories with courtly gossip.

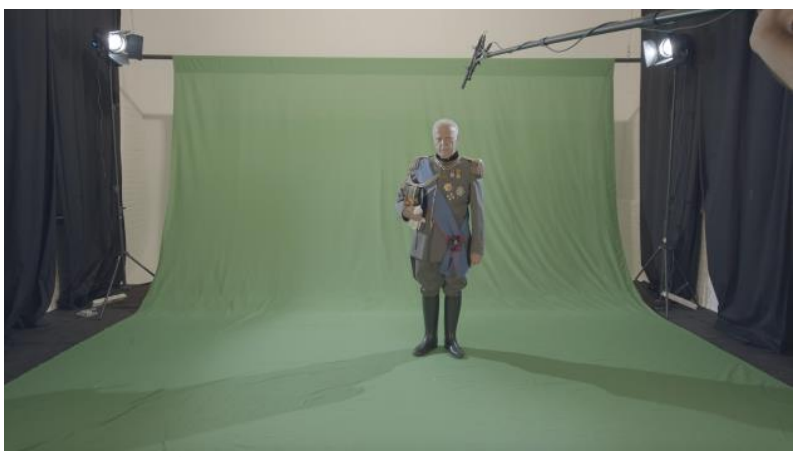

Figure 4: Green screen shooting of actors in historical dress

The actors who played these roles shot the various scenes on the green screen, in pre-established positions, following narrative, compositional and functional logics. The characters inserted in postproduction in the virtual environments together with the furniture were modified to transform them into the ghosts of the past. The sound element is also important in the experience because it manages to direct the visitor's attention to the precise point where the narration takes place, through the spatialisation of the audio, despite the freedom of exploration.

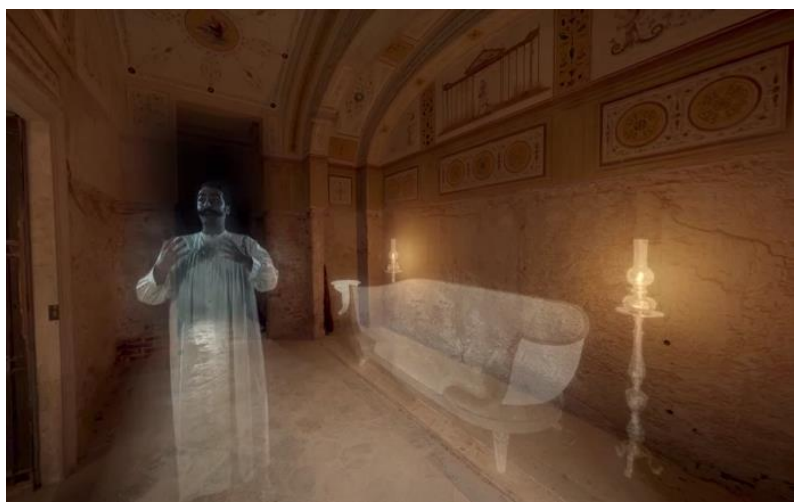

Figure 5: VR image of King Carlo Alberto's ghost and furniture

\subsection{Narrative structure}

The user who lives the experience is considered as a visitor both in reality and in the virtual world. Wearing the visors, the user finds himself catapulted into the gardens of the Castle, just outside the thermal baths, where, attracted by a voice, that of the ghost of King Carlo Alberto, he is welcomed inside and given some initial indications on how to move and what to expect during his exploration. Visitors will be able to recognise the room they are in by the signs at the foot, where the name will appear. The journey through the different rooms begins in the Ironing Room, a place used by the servants to dry the palace's linen, where the first ghost appears, that of the servant Benedetta and all the furnishings that used to fill the room. Here the life of the court is illustrated and the functioning of one of the machines of the time, still present in the room, is shown in action through an animation. The tour continues in the other rooms, where Benedetta continues with her story, until King Carlo Alberto and then King Vittorio Emanuele III enter on stage. The three timelines on which the narrative unfolds intertwine throughout the experience: the first line is represented by the moment when the visitor participates in the exhibition of the places during the restoration phase; the second, set in 1842, coincides with the appearance of Benedetta and King Carlo Alberto; the last time jump is to 1920, represented by the appearance of King Vittorio Emanuele III, who will take the place of King Carlo Alberto in the last room.

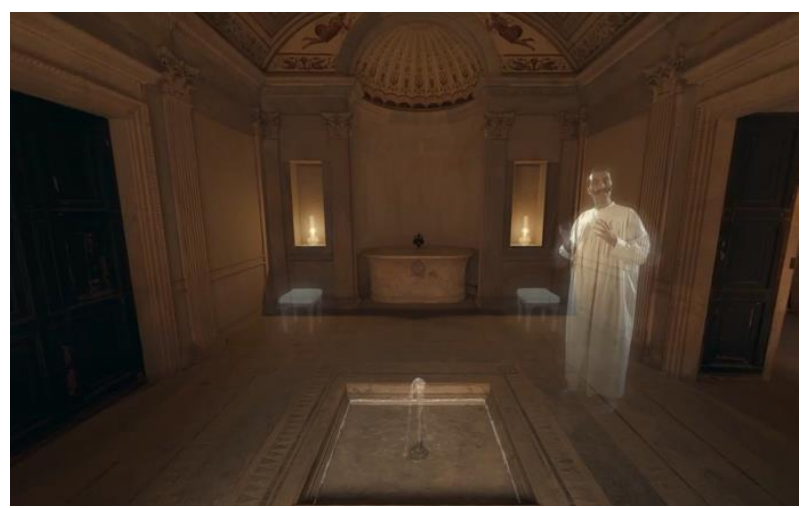

Figure 6: VR image of King Carlo Alberto's ghost on stage

The narrative trend curve of the project experience continues slowly, leading the user considered as a hero to meet emblematic figures of increasing importance. Once arrived at the last rooms there are two peaks in the narrative: the first occurs with the appearance of King Carlo Alberto, and the second with the entrance of his twentieth-century successor King Vittorio Emanuele III, who reaches the scene a few moments before the closing of the experience with the wish to meet the visitors again.

The development of the narrative was studied in close correlation with the classic curve of attentional state (which starts very high and then falls after the first few minutes and rises again towards the end of the activity), and the difficulty curve in this case referred to the energies required to process the contents, rather than to an increase in the complexity of interaction with the environment.

It was considered in each room to be visited an extra time at the end of each narrative for free exploration by the visitor of 15 seconds, supported by the textual, iconographic and sound compendium through: descriptions and faithful quotations of the artists who made those rooms and music by composers of the time related to the royal court. 


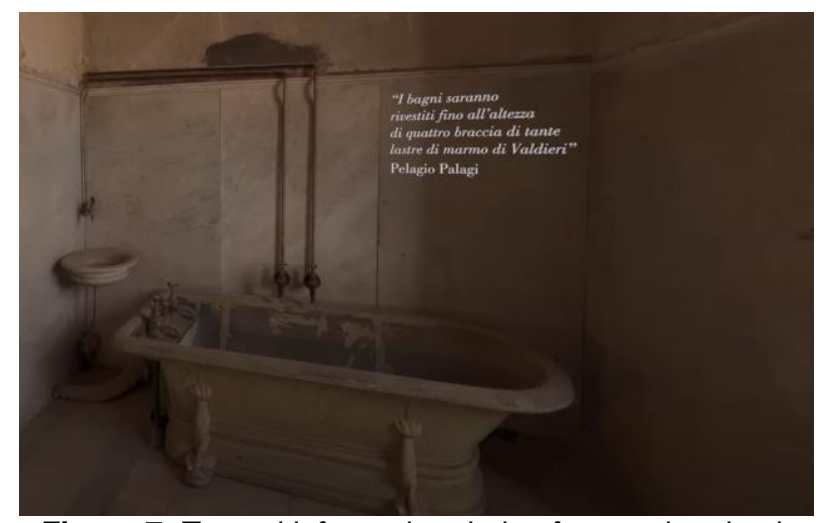

Figure 7: Textual information during free exploration in VirgilTell

\section{EXPERIENCE MANAGEMENT}

The VirgilTell experience is designed to be long enough to present the right amount of information and allow the audience to process the stimulation and maintain a high state of attention. From the moment the playback begins, the experience lasts 10 minutes, and each room visited is alternated with 15 seconds for orbital exploration following the content played in each room.

The experience takes place in spaces adjacent to the restored site, where there are 8 stations set up for the virtual visit using Oculus Quest. During the visit, visitors are seated in swivel chairs that provide the physical support necessary to view the experience without incurring episodes of physical fatigue or disorientation, dizziness or collisions with other members of the group and the surrounding environment.

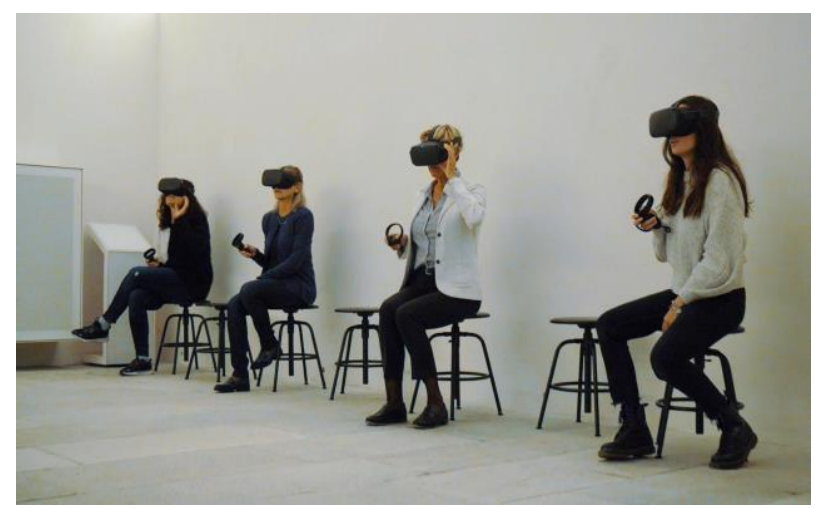

Figure 8: Test of VirgilTell experience with museum staff

Once the visors are seated, the experience will be activated simultaneously in all the visors, by a device controlled by the museum guide, in order to avoid overlapping sounds between the different users. The experience can be interrupted at any time.

In the following phases, the service will be tested with visitors to collect data on the evaluation of the perceived quality and their emotional reaction to the experience.

\section{CONCLUSION}

The topic of improving and enhancing the enjoyment of cultural heritage through the application of digital technologies is a very recurrent one, especially at a time in history when we are reflecting on new forms of visiting museums. The adoption of technology in museums must be designed as an integral part of the context in which it is used and not considered as an accessory to the visiting experience. Considerations of usability, usefulness, effectiveness and management of the technological tool are necessary for its acceptance. In this sense, in-depth knowledge of the audience is a fundamental element to meet the creation of cultural content that can be enjoyed on a large scale, where the cognitive factor combines with the emotional one (Hassenzahl 2003).

For an ethical approach to the project, the reflection on the opportunities offered by different technologies allows to arrive at an experience that is contextual and appropriate to the message to be conveyed to the public. The visitor is attracted by the ability to tell stories with which they can empathise, where an authentic and unprecedented point of view is presented and where they feel like protagonists of a new reality (Han, tom Dieck \& Jung 2017). These reflections supported the evolution of the project from Virgil Robot to VirgilTell, for visiting inaccessible spaces, which placed particular emphasis on aspects relating to the acceptance of technology, both by visitors and museum guides, for the development of the service. It is still evident that the entry of these technologies into museum systems does not take into account the service management of museum guides, who have to interact with complex and cumbersome systems (Shehade \& StylianouLambert 2020). Through the VirgilTell experience, an attempt has been made to reduce the responsibility of the museum guide and to make the service easy to manage.

It is evident that technologies such as VR and AR allow not only scalability, but also the continuous possibility to update content and implement the experience. The contribution intends to open a reflection on the impact of innovative elements such as VR and AR combined with the museum context to improve the visitor experience and satisfaction. The VirgilTell project intends to contribute to the debate on the new museology for the creation of methodological models scalable to different realities for the use of evolving museum spaces. 


\section{REFERENCES}

Barbieri, L., Bruno, F., \& Muzzupappa, M. (2017) User-centered design of a virtual reality exhibit for archaeological museums. International Journal on Interactive Design and Manufacturing (IJIDeM), 12(2), 561-571. doi:10.1007/s12008-017-0414-z

Bekele, M. K., Pierdicca, R., Frontoni, E., Malinverni, E. S., \& Gain, J. (2018) A Survey of Augmented, Virtual, and Mixed Reality for Cultural Heritage. Journal on Computing and Cultural Heritage, 11(2), 1-36. doi:10.1145/3145534

Bozzelli, G., Raia, A., Ricciardi, S., Nino, M. D., Barile, N., Perrella, M., Tramontano, M., Pagano, A., Palombini, A. (2019) An integrated VR/AR framework for user-centric interactive experience of cultural heritage: The ArkaeVision project. Digital Applications in Archaeology and Cultural Heritage, 15. doi:10.1016/j.daach.2019.e00124

Chung, N., Lee, H., Kim, J., \& Koo, C. (2017) The Role of Augmented Reality for ExperienceInfluenced Environments: The Case of Cultural Heritage Tourism in Korea. Journal of Travel Research, 57(5), 627-643. doi:10.1177/0047287517708255

Han, D., Dieck, M. C., \& Jung, T. (2017) User experience model for augmented reality applications in urban heritage tourism. Journal of Heritage Tourism, 13(1), 46-61. doi:10.1080/1743873x.2016.1251931

Hassenzahl, M. (2003) The thing and I: understanding the relationship between user and product. In M. A. Blythe, K. Overbeeke, A. F. Monk \& P. C. Wright (Eds.), Funology (pp. 31-42). Dordrecht: Kluwer Academic Publishers

He, Z., Wu, L., \& Li, X. (2018). When art meets tech: The role of augmented reality in enhancing museum experiences and purchase intentions. Tourism Management, 68, 127-139. doi:10.1016/j.tourman.2018.03.003

Istat (2019) L'Italia dei musei, Italy, 23 December, https://www.istat.it/it/archivio/237159

Kargas, A., Karitsioti, N., \& Loumos, G. (2020) Reinventing Museums in 21st Century. Virtual and Augmented Reality in Education, Art, and Museums Advances in Computational Intelligence and Robotics, 117-138. doi:10.4018/978-1-79981796-3.ch007

Koslow, J. (2019) Museums and digital culture: New perspectives and research. Museum Management and Curatorship, 34(5), 537-539. doi:10.1080/09647775.2019.1661098
Lee, H., Jung, T. H., Dieck, M. T., \& Chung, N. (2020) Experiencing immersive virtual reality in museums. Information \& Management, 57(5), 103229. doi:10.1016/j.im.2019.103229

Lupetti, M. L., Germak, C., \& Giuliano, L. (2015) Robots and Cultural Heritage: New Museum Experiences. doi:10.14236/ewic/eva2015.36

Pine, B. J., \& Gilmour, J. H. (n.d.) The experience economy: Work is theatre \& every business a stage. Harvard Business School Press.

Rae, J, \& Edwards, L. (2016) Virtual reality at the British Museum: What is the value of virtual reality environments for learning by children and young people, schools, and families?." MW2016: Museums and the Web 2016. Published January 28, 2016. Consulted March 17, 2021

Roggero, C., \& Vanelli, A. (2009) Le residenze Sabaude. Umberto Allemandi \& C.

Sacco, P. L., Ferilli, G., Blessi, G. T., \& Nuccio, M. (2013) Culture as an engine of local development processes: System-wide cultural districts I: Theory. Growth and Change, 44(4), 555-570. https://doi.org/10.1111/grow.12020

Schaper, M., Santos, M., Malinverni, L., Berro, J. Z., \& Pares, N. (2018) Learning about the past through situatedness, embodied exploration and digital augmentation of cultural heritage sites. International Journal of Human-Computer Studies, 114, 36-50. doi:10.1016/j.jhcs.2018.01.003

Shehade, M., \& Stylianou-Lambert, T. (2020) Virtual Reality in Museums: Exploring the Experiences of Museum Professionals. Applied Sciences, 10(11), 4031. doi:10.3390/app10114031

Southall, H., Marmion, M., \& Davies, A. (2019) Adapting Jake Knapp's Design Sprint Approach for AR/VR Applications in Digital Heritage. Augmented Reality and Virtual Reality Progress in IS, 59-70. doi:10.1007/978-3-030-06246-0_5

Trunfio, M., Lucia, M. D., Campana, S., \& Magnelli, A. (2021) Innovating the cultural heritage museum service model through virtual reality and augmented reality: The effects on the overall visitor experience and satisfaction. Journal of Heritage Tourism, 1-19. doi:10.1080/1743873x.2020.1850742

Tscheu, F., \& Buhalis, D. (2016) Augmented reality at cultural heritage sites. In Information and communication technologies in tourism 2016 (pp. 607-619). Cham: Springer. 